\title{
THE POSITRON EMISSION TOMOGRAPHY IN EARLY DIAGNOSTICS OF THE METABOLIC MYOCARDIAL DISORDERS IN INSULIN-RESISTANT PATIENTS WITH NON-ALCOHOLIC FATTY LIVER DISEASE
}

\section{ПОЗИТРОННО-ЭМИССИОННАЯ ТОМОГРАФИЯ КАК ЭФФЕКТИВНЫЙ МЕТОД РАННЕЙ ДИАГНОСТИКИ МЕТАБОЛИЧЕСКИХ НАРУШЕНИЙ МИОКАРДА У ПАЦИЕНТОВ С НЕАЛКОГОЛЬНОЙ ЖИРОВОЙ БОЛЕЗНЬЮ ПЕЧЕНИ}

\author{
ROYTBERG, Grigory Efimovich ${ }^{1}$; SHARKHUN, Olga Olegovna ${ }^{*}$; \\ PLATONOVA, Oksana Evgenyevna ${ }^{3}$; STEPANOVA, Anna Alexandrovna ${ }^{4}$; \\ 1,2 Pirogov Russian National Research Medical University, Moscow, Russian Federation \\ 3,4 Joint Stock Company «Medicina», Moscow, Russian Federation \\ * Correspondence author \\ e-mail: olga_sharkhun@mail.ru
}

Received 19 December 2019; received in revised form 20 February 2020; accepted 19 March 2020

\section{RESUMO}

Recent studies demonstrated the Hepato-cardiac relationship in patients with non-alcoholic fatty liver disease as subclinical, structural, and functional alterations in the heart. However, the mechanisms underlying the changes in the cardiovascular system are understudied and not clear. The aim of the study was to assess glucose metabolism, its perfusion in the cardiomyocytes and the detection of the myocardial dysfunction in patients with fatty liver disease and insulin resistance using the positron emission tomography with fludeoxyglucose. During the study, 18 patients (14 men and 4 women, mean age $52 \pm 4.2$ years) with the non-alcoholic fatty liver disease and the insulin resistance (HOMA-IR>2.6) were examined. There were 12 patients in the control group. Echocardiography revealed various types of the left ventricular cardiac remodeling in the study group: $44.4 \%$ of patients with eccentric hypertrophy, $38.9 \%$ with concentric hypertrophy, and $16.7 \%$ with the concentric remodeling. In this group, there was a pronounced diffuse uneven distribution of the radiopharmaceutical. In addition, zones of hypometabolism and paradoxical accumulation of glucose were detected. Thus, it was shown that in patients with non-alcoholic fatty liver disease and insulin resistance, the intensity and nature of glucose metabolism in cardiomyocytes changed, indicating the presence of myocardial metabolic dysfunction. We believe that the systemic insulin resistance metabolic processes were disturbed not only in the liver cells but also in the cardiomyocytes. As a result of the metabolic dysfunction, the geometric parameters of the heart are changed, and various types of cardiac remodeling are formed.

Palavras-chave: fatty liver disease, insulin resistance, metabolic dysfunction.

\section{ABSTRACT}

Recent studies demonstrated the Hepato-cardiac relationship in patients with non-alcoholic fatty liver disease as subclinical, structural, and functional alterations in the heart. However, the mechanisms underlying the changes in the cardiovascular system are understudied and not clear. The aim of the study was to assess glucose metabolism, its perfusion in the cardiomyocytes and the detection of the myocardial dysfunction in patients with fatty liver disease and insulin resistance using the positron emission tomography with fludeoxyglucose. During the study, 18 patients (14 men and 4 women, mean age $52 \pm 4.2$ years) with the non-alcoholic fatty liver disease and the insulin resistance (HOMA-IR>2.6) were examined. There were 12 patients in the control group. Echocardiography revealed various types of the left ventricular cardiac remodeling in the study group: $44.4 \%$ of patients with eccentric hypertrophy, $38.9 \%$ with concentric 
hypertrophy, and $16.7 \%$ with the concentric remodeling. In this group, there was a pronounced diffuse uneven distribution of the radiopharmaceutical. In addition, zones of hypometabolism and paradoxical accumulation of glucose were detected. Thus, it was shown that in patients with non-alcoholic fatty liver disease and insulin resistance, the intensity and nature of glucose metabolism in cardiomyocytes changed, indicating the presence of myocardial metabolic dysfunction. We believe that the systemic insulin resistance metabolic processes were disturbed not only in the liver cells but also in the cardiomyocytes. As a result of the metabolic dysfunction, the geometric parameters of the heart are changed, and various types of cardiac remodeling are formed.

Keywords: fatty liver disease, insulin resistance, metabolic dysfunction.

\section{АННОТАЦИЯ}

Недавние исследования продемонстрировали гепатокардиальные отношения у пациентов с неалкогольной жировой болезнью печени как субклинические структурные и функциональные изменения в сердце. Однако механизмы, лежащие в основе данных изменений, недостаточно изучены и не совсем понятны. Целью исследования было оценить метаболизм глюкозы, ее перфузию в кардиомиоцитах и выявление дисфункции миокарда у пациентов с неалкогольной жировой болезнью печени и инсулинорезистентностью с использованием метода позитронно-эмиссионной томографии с использованием фтордезоксиглюкозы. В нашем исследовании было обследовано 18 пациентов (14 мужчин и 4 женщины, средний возраст $52 \pm 4,2$ года) с НАЖБП и инсулинорезистентностью (HOMA-IR> 2,6). В контрольной группе было 12 пациентов. Эхокардиография выявила различные типы ремоделирования левого желудочка в основной группе: 44,4\% пациентов с эксцентрической гипертрофией, 38,9\% с концентрической гипертрофией и 16,7\% с концентрическим ремоделированием. В контрольной группе пациентов с ремоделированием сердца не было. В этой группе при проведении позитронно-эмиссионной томографии установлено равномерное распределение фторглюкозы в сердечной мышце, и структура миокарда была относительно однородной. В основной группе наблюдалось выраженное диффузное неравномерное распределение радиофармпрепарата. Кроме того, были обнаружены зоны гипометаболизма и парадоксального накопления глюкозы. Мы полагаем, что при системной инсулинорезистентности метаболические процессы нарушаются не только в клетках печени, но и в кардиомиоцитах. В результате метаболической дисфункции изменяются геометрические параметры сердца и формируются различные типы ремоделирования сердца.

Ключевые слова: жировая болезнь печени, инсулинорезистентность, метаболическая дисфункция.

\section{INTRODUCTION}

Presently, positron-emission tomography (PET) is widely used in different areas of medicine, for example, in oncology, for the diagnostics of tumors of different localization, in cardiology, for the evaluation of the myocardium damage and myocardial blood supply rate, in neurology, for the diagnostics of Alzheimer disease (Usov et al.,2014; Buziashvili and Buziashvili, 2014; Cohn, 1998). The method allows the specialists to combine computer tomography and the introduction of short half-life isotopes that are necessary for the evaluation of the functional activity of the studied tissue. The main advantage of the method is the possibility of the evaluation of energetic metabolic disturbances of the studied organ (Nikiforov, 2017; Yoshinaga and Tamaki, 2007 ).

Energetic metabolism of the myocardium is a many-staged process that includes the formation of a highly allergic compound, adenosine triphosphoric acid (ATP), in mitochondria, intercellular transport of ATP molecules and their utilization during the energydependent vital processes (Parmon and Ryzhova, 2014; Sergienko and Babev, 2011). The main metabolic sources of biological synthesis of ATP are long-chained free fatty acids (FFA) and glucose that provide normal functioning of the enzymes of the breathing chain in mitochondria and regulate the process of oxidative phosphorylation with the formation of ATP (Usov et al., 2014; Ryotberg and Sharkhun, 2017b). In normal physiologic conditions, the utilization of fatty acids and carbohydrates is absolutely balanced and depends on the availability of each of these substrates. When the consumption of oxygen is sufficient $(60-80 \%)$, ATP is synthesized due to the oxidation of long-chained FFA. However, in comparison with glucose, fatty acids are considered to be a less feasible source of 
energy because, for the oxidation of the same amount of ATP, it is required to spend $10 \%$ more oxygen. The involvement of FFA in energy metabolism is reduced during physical load, in stress situations, in smokers, in the condition of hypoxia, and in patients with hyperglycemia or hyperinsulinemia. Insulin resistance in tissues and disturbance of glucose transport are associated with mitochondrial dysfunction and, as a result, the disturbances of energy metabolism in cells, including cardiomyocytes. In such conditions, the rate of beta-oxidation of FFA significantly decreases, and glycolysis becomes the main source of ATP for the cells (Bokeria, 2010; Yoshinaga and Tamaki, 2007). Hence, the quantitative evaluation of the utilization rate of glucose can be used for the study of the activity of this metabolic pathway for the evaluation of the functional status of the myocardium. Presently, the most informative method is positron emission tomography with fluorodeoxyglucose (18F-FDG). When 18F-FDG gets into a cell, it phosphorylates due to hexokinase to fluorodeoxyglucose-6phosphate, a compound that does not get involved in further metabolic reactions. Since it cannot penetrate through a cellular membrane, the transport of ${ }^{18} \mathrm{~F}-\mathrm{FDG}$ to a cell is irreversible. Thus, the accumulation of ${ }^{18} \mathrm{~F}-\mathrm{FDG}$ in the myocardium correlates with the consumption of glucose and can be used for the estimation of the rate of its utilization and identification of the activity of glycolysis.

It is established that the disturbance of carbohydrate and lipid metabolism is determined pathogenically by the condition of the liver (Björnsson et al., 2013; Musso et al., 2012). According to the opinion of the leading organizations in hepatology, the presence of the signs of hepatic steatosis and the absence of secondary fat accumulation is treated as nonalcoholic fatty liver disease (NAFLD). NAFLD is closely associated with metabolic syndrome and its components: abdominal obesity, dyslipidemia, hyperglycemia, atherosclerosis, and arterial hypertension. In its turn, NAFLD is not only an additional risk factor for the development of cardiovascular diseases but also a factor that determines the outcome of liver disease (Ryotberg and Sharkhun, 2017b). There are data on the presence of Hepato-cardiac associations that are characterized by the change in the geometry of the heart, structural-functional parameters of the heart, and diastolic dysfunction in patients with NAFLD (Björnsson et al., 2013; Musso et al., 2012) However, the mechanisms underlying the alteration in the cardiovascular system remain understudied and unclear, which defines the aims and tasks of further studies.

The aim of the present study was to evaluate glucose metabolism, condition of its perfusion in the myocardium, and myocardial dysfunction in patients with non-alcoholic fatty liver disease and insulin resistance.

\section{MATERIALS AND METHODS}

The authors examined two groups of patients at the clinics of JSC "Medicine". Group I included 18 patients with clinical and laboratoryinstrumental signs of NAFLD. Group II (control group) included 12 people who did not have signs of NAFLD and met the study exclusion criteria. The study exclusion criteria were diabetes mellitus 1 and 2 types, lipid metabolism disorders (including congenital disorders and hypolipidemic therapy), arterial hypertension that requires therapeutic correction, ischemic heart disease, obesity of II and III degrees, serious somatic diseases at the stage of decompensation, and hormonal replacement therapy.

NAFLD was diagnosed based on the performed examination as a diagnosis of the exclusion of other hepatic pathology in patients with ultrasound signs of fatty hepatosis. Insulin resistance (IR) in patients was evaluated with a laboratory model of the evaluation of homeostasis (HOMA-IR) by Equation 1.

HOMA-IR $=\left(G_{b f}{ }^{*} I_{b m}\right) / 22.5$

(Eq. 1)

Where $\mathrm{G}_{\mathrm{bf}}=$ (Glucose before meal $(\mathrm{mmol} / \mathrm{L}) ; \quad \mathrm{I}_{\mathrm{bm}}=$ Insulin before the meal $(\mathrm{mcU} / \mathrm{ml})) / 22.5$

According to the recommendation of the $\mathrm{WHO}$, in the clinical practice, the upper quartile of the HOMA-IR distribution index in the general population is to be used for the evaluation of IR. Thus, threshold resistance to insulin, expressed in HOMA-IR, is defined as 75 percentile of its cumulative populational distribution. In the present study, the threshold value of HOMA was 2.6 points. IR was diagnosed in patients at HOMA-IR higher than 2.6 points.

All the patients had an echocardiographic study performed with an apparatus "Vivid E80" ("GE Healthcare"). The main geometry parameters of the left ventricle (LV) included the 
end-diastolic dimension of LV, crosscut dimension, longitudinal dimension of $V L$ in diastole (DLV), left ventricular posterior wall thickness, interventricular septum thickness in diastole (ISTD). Parameters of the geometry of LV were used for the calculations of indexes reflecting the process of its remodeling: sphericity index - the relation of the cross-sectional dimension of LV to its long axis, myocardial mass index (MMI) of LV (was identified by the formula of R. Devereux and N. Reichek), index of the relative thickness of the wall (RTW) - the ratio of a sum of LV PWT and IWST to LV EDD. Depending on the values of these indexes, different types of LV geometry remodeling are identified (by the classification of A. Ganau, 1992): normal geometry of LV (RWT $\leq 0.42$ and $\mathrm{MMI} \leq 95 \mathrm{~g} / \mathrm{m}^{2}$ for women and $\leq 115 \mathrm{~g} / \mathrm{m}^{2}$ for men), concentric hypertrophy of LV: RWT $>0.42$ and $\mathrm{MMl}>95 \mathrm{~g} / \mathrm{m}^{2}$ for women and $>115 \mathrm{~g} / \mathrm{m}^{2}$ for men; eccentric hypertrophy: RWT $\leq 0.42$ and $\mathrm{MMl}>95 \mathrm{~g} / \mathrm{m}^{2}$ for women and $>115 \mathrm{~g} / \mathrm{m}^{2}$ for men, concentric remodeling: $\mathrm{RTW}>0.42$ and $\mathrm{MMI} \leq 95 \mathrm{~g} / \mathrm{m}^{2}$ for women and $\leq 115 \mathrm{~g} / \mathrm{m}^{2}$ for men.

All PET-CT studies were performed with "Biograph mCT Flow 64-4R PET/CT system" (Siemens Healthcare, Germany). The procedure was performed before a meal at rest for the exclusion of the negative influence of hyperinsulinemia on the accumulation of radiopharmaceutical agent (RPA) in the myocardium. The study was performed in a static mode on a reconstructed image that clearly visualized the left ventricle. For the analysis, the zones of interest were chosen that corresponded to the myocardium of LV. The image processing was performed by the cut sections that were formed by the vertical, horizontal, and short axes of LV with a section cut the thickness of $0.5 \mathrm{~cm}$. Visual analysis of the images was performed with a color scale that allowed the authors to evaluate the intensity of RPA accumulation in focus, its localization, dimensions, contours, and character of the drug distribution.

\section{RESULTS AND DISCUSSION}

Eighteen patients were selected in the study group (14 men and 4 women, average age $52 \pm 4.2$ years old). All the patients were preliminary examined and had clinical and laboratory-instrumental signs of NAFLD revealed. There were two forms of this disease revealed: nonalcoholic steatosis (liver fatty degeneration at a normal level of aminotransferases) and nonalcoholic steatohepatitis (with an increase in the level of hepatic enzymes in the blood) in 12 and 6 patients, respectively. The calculated laboratory index HOMA-IR exceeded the threshold values in all the patients from the study group and was equal to $4.41 \pm 3.8$, which indicated insulin resistance in this category of patients. The control group included 12 patients ( 5 men and 7 women, average age $44 \pm 6.5$ years old) that did not have signs of NAFLD. The patients did not have signs of disturbances of carbohydrate metabolism and insulin resistance (HOMA-IR $1.29 \pm 0.98)$.

Echocardiogram in patients from the study group revealed the alterations of the heart chambers dimensions in comparison with the control group. Thus, average values of LV EDD were $4.87 \pm 0.38 \mathrm{~cm}$ vs. $4.73 \pm 0.32 \quad(p<0.05)$, average values of $L V$ longitudinal dimension (DLV) were $7.87 \pm 0.86$ vs. $8.38 \pm 0.50 \quad(p<0.05)$. The Index of sphericity (IS) of LV, as a relation of a cross-section of LV to its long axis, in normal condition does not exceed 0.6 and characterize an ellipsoid shape of LV. In the present study, the patients with NAFLD and IR had an average IS higher than the norm and significantly different from the patients in the control group: $0.62 \pm 0.06$ vs. $0.58 \pm 0.05,(p<0.05)$. In the majority of patients from the study group, this parameter was higher than 6 in 13 out of 18 patients, which was $72.2 \%$. The increase in the IS was higher than 0.6, which indicated the alterations in the geometry of the heart with a tendency to the formation of spherical shape.

The average values of LV PWT and IVST were $0.99 \pm 0.12 \mathrm{~cm}$ and $1.01 \pm 0.13 \mathrm{~cm}$, respectively, in the control group. The calculation of the index of relative wall thickness (RWT) of LV (relation of a sum of LV PWT and IVST to LV EDD) in 7 out of 18 (38.9\%) patients from the study group showed higher values of normal values. In the control group, these values did not exceed the normal value in all the patients. LV MMI was calculated automatically. According to the Russian Medical Society on Arterial Hypertension (2013), LV MMI in men did not exceed $115 \mathrm{~g} / \mathrm{m}^{2}$, in women $-95 \mathrm{~g} / \mathrm{m}^{2}$. In the present study, the average values of the LV MMI parameter exceeded the norm only in the group of patients with IR and NAFLD and were equal to $116.61 \pm 11.03 \mathrm{~g} / \mathrm{m}^{2}$ and $96.03 \pm 7.46 \mathrm{~g} / \mathrm{m}^{2}$, respectively. Based on the obtained data, the indexes RWT and LV MMI were used for the evaluation of the heart geometry and establishment of the type of LV remodeling. The distribution of patients by different types of remodeling is presented in Table 1. 
Table 1. Distribution of the remodeling types of the left ventricle in the studied group.

\begin{tabular}{|c|c|c|}
\hline $\begin{array}{l}\text { Geometric } \\
\text { model of LV }\end{array}$ & $\begin{array}{c}\text { Echocardiogram } \\
\text { parameters }\end{array}$ & $\begin{array}{c}\text { Number } \\
\text { of } \\
\text { patients }\end{array}$ \\
\hline \multirow{2}{*}{$\begin{array}{c}\text { Eccentric } \\
\text { hypertrophy }\end{array}$} & RWT $\leq 0.42$ & $n=8$ \\
\hline & $\begin{array}{c}\mathrm{MMI}>95 \mathrm{~g} / \mathrm{m}^{2} \mathrm{O}, \\
>115 \mathrm{~g} / \mathrm{m}^{2}{ }^{\lambda}\end{array}$ & $44.4 \%$ \\
\hline \multirow{2}{*}{$\begin{array}{c}\text { Concentric } \\
\text { hypertrophy }\end{array}$} & RWT > 0.42 & $\mathrm{n}=7$ \\
\hline & $\begin{array}{c}\mathrm{MMI}>95 \mathrm{~g} / \mathrm{m}^{2}{ }^{+} \\
>115 \mathrm{~g} / \mathrm{m}^{2}\end{array}$ & $38.9 \%$ \\
\hline \multirow{2}{*}{$\begin{array}{l}\text { Concentric } \\
\text { remodeling }\end{array}$} & RWT > 0.42 & $n=3$ \\
\hline & $\begin{array}{c}\mathrm{MMI} \leq 95 \mathrm{~g} / \mathrm{m}^{2}{ }^{+} \\
\leq 115 \mathrm{~g} / \mathrm{m}^{2}{ }^{7}\end{array}$ & $16.7 \%$ \\
\hline
\end{tabular}

The results of the performed examination showed that in the study group, the hypertrophic variants of the remodeling prevailed. In $44.4 \%$ $(8 / 18)$ of patients, it was eccentric hypertrophy and $38.9 \%(7 / 18)$ of patients - concentric hypertrophy of LV. Concentric remodeling of LV was observed only in $16.7 \%$ (3/18) of patients. Prognostically hypertrophic variants of the heart geometry were less favorable in terms of the development of rhythm disturbances and persistent arterial hypertension.

In the control group, PET-CT with 18FFDG showed even distribution of RPA in the myocardium. The myocardium structure was relatively consistent. This picture was taken as a variant of normal, even glucose uptake by cardiomyocytes. The analysis of the character of the distribution of RPA in the group of patients with NAFLD and IR showed the following alterations. The authors evaluated the density of hepatic tissue that was lower than the normal level and equal to $38.4 \pm 3.2 \mathrm{HU}$ (at normal values of liver density $50 \mathrm{HU}$ ). The evaluation of the metabolic activity of myocardium in this group of patients and visual analysis revealed an expressed uneven diffusive distribution of RPA. Such manifestations primarily reflect anatomic (histologic) inconsistency of the myocardium. It is not always associated with the reduction of myocardial blood circulation, and in the present study, the heterozygosity of the distribution of RPA can indicate zones of fibrosis or fat tissue in the myocardium. Such diffusive inconsistency of the image in 12 patients $(66.7 \%)$ from this group revealed the zones of hypometabolism (decrease in the accumulation of RPA). The area of these zones did not exceed $12.24 \mathrm{~cm}^{2}$ (maximum value). Such a decrease in the glucose uptake by the myocardium was observed in patients with concentric (5 patients) and eccentric (7 patients) hypertrophy of LV. Along with the patients that had a decreased accumulation of RPA, there were patients with minor $(5-7 \mathrm{~mm})$ zones of paradoxical accumulation of glucose. In 2 patients $(11.1 \%)$, zones of hypermetabolism (7.8 and $3.4 \mathrm{~cm}$ ) with increased accumulation of RPA were revealed. However, they did not form sectors that corresponded to a pool of a certain artery, and, probably, they were the reflections of the zones of fatty infiltration or fibrotic alterations in the myocardium. Echocardiogram showed that these patients had a concentric type of remodeling of LV. Thus, it was established that patients with NAFLD and IR with altered geometry of the heart, the sphericity of LV myocardium, and different type of remodeling in cardiomyocytes had an intensity and character of glucose metabolism changed, which indicates myocardial metabolic dysfunction.

Presently, a close association between NAFLD and metabolic syndrome and its components is established. In patients with NAFLD, lipid and carbohydrate metabolism disturbances aggravate, atherogenic types of dyslipidemias develop, the risk of atherosclerosis and the incidence rate in patients with arterial hypertension increase (Roytberg et al., 2017a; Lazebnik et al., 2017; Drapkina, 2011). Recent studies demonstrated the formation of hepatocardial associations in patients with fatty hepatosis in the form of structural-functional alterations in the heart. It was shown that patients with NAFLD had early left ventricular diastolic dysfunction developed (Bonapace et al., 2012; Mantovani et al., 2015), dimensions of heart chambers, and interventricular septum thickness altered (Drapkina, 2011). Besides, the patients with steatohepatitis had altered hemodynamics in the form of luminal narrowing of the aorta that was associated with atherosclerosis and mitral and aortal valves alterations of atherosclerotic nature in comparison with patients that did not have hepatic disorders. According to the published data, patients with NAFLD have elevated risk of the development of cardiovascular events (myocardial infarction, arrhythmia, stroke, sudden cardiac arrest, congestive heart failure). However, pathways and mechanisms of mutual influence of the structuralfunctional condition of the liver and heart in patients with metabolic disorders remain unclear. 
The authors of the present study analyzed the possible mechanisms underlying the alterations in the myocardium in patients with fatty degeneration of the liver. Since NAFLD is associated with the sensitivity of tissues to insulin, the study group included patients with two main criteria: clinical and laboratory-instrumental signs of NAFLD and signs of IR diagnosed by the index HOMA-IR. It can be suggested that in patients with systemic IR, metabolic processes get disturbed not only in hepatocytes but also in cardiomyocytes, the rate of glucose utilization, and it's transmembrane transport to cardiomyocytes changes. The development of metabolic dysfunction leads to alterations in the geometry of the heart and the formation of different types of remodeling of LV (Figure 1).

The study of perfusion and metabolism of glucose in the myocardium is an important mechanism in the understanding of pathophysiological grounds of structuralfunctional alteration in the heart and its remodeling in patients with NAFLD and IR. PETCT with 18F-FDG showed diffusive heterogeneity of the perfusion of the isotope marked glucose in all the patients from this group, a decrease in the uptake of glucose by cardiomyocytes in $66.7 \%$ of cases and its paradoxical accumulation in $22.2 \%$. The defects of perfusion were observed in $37.5 \%$ of cases. However, they did not form sectors that corresponded to a respective pool of a certain artery. Probably, these defects reflect the zones of fibrosis or fatty inclusions. Probably, they are observed due to the alterations in the microcirculatory bloodstream. The pathology of intramural microvessels like arterioles, capillaries, venules, and arteriole-venular anastomosis, that provide blood filling, intervascular exchange, and tissue homeostasis in the myocardium, play an important role in this processes (Drapkina, 2011; Yoshinaga and Tamaki, 2007). According to the published data, patients with metabolic syndrome had pathologic alterations in $30-50 \%$ of cases (biopsy of the myocardium) (Cunningham, 2006; Yamamoto, 2002). It is suggested that the pathogenesis of the coronary circulation disorders is based on the reversible processes (endothelial dysfunction, rheological blood disorders, diastolic dysfunction, disbalance in the vegetative nervous system) and irreversible alterations (vascular walls remodeling, the imbalance between the number of capillaries and the mass of heart, like heart hypertrophy) (Cohn, 1998). Perfusion disorders in the myocardium in patients with insulin resistance can also be associated with endothelial dysfunction of the vessels, in particular, decrease in the production of endogenous vasodilator nitrogen oxide that is produced by the endothelium (Usov et al., 2014; Buziashvili and Buziashvili, 2014). Thus, a complex of the mechanisms that are pathogenetically associated with insulin resistance, metabolic disorders, and pathological alterations in the liver plays an important role in the development of metabolic dysfunction of the myocardium.

\section{CONCLUSION}

The results of the present study showed that patients with NAFLD and IR had altered geometry of the heart and prognostically unfavorable hypertrophic types of left ventricle remodeling (eccentric, concentric hypertrophy of LV). Hepato-cardiac associations are based on the disturbed sensitivity of cardiomyocytes to insulin and glucose metabolism disorders that contribute to the development of metabolic myocardial dysfunction. Presently, it is difficult to evaluate the cause-effect relations in the Hepatocardiac associations. However, it is clear that NAFLD is a predictor of heart dysfunctions due to the decrease in glucose metabolism in cardiomyocytes. Further studies are needed for the understanding of clinical importance of the identification of perfusion-metabolic alterations in the myocardium and their prognostic significance.

\section{REFERENCES}

1. Altehoefer, C.; Vom Dahl, J.; Bares, R.; Stöcklin, G. L.; Büll, U. Metabolic mismatch of septal beta-oxidation and glucose utilization in left bundle branch block assessed with PET. J. Nucl. Med, 1995, 36, 2056-2059

2. Bokeria, L. A.; Shurupova, I. V.; Asladini, I. P. Evaluation of the perfusion and metabolism in patients with dilated cardiomyopathy. Creative cardiology, 2010, 1, 43-54.

3. Bonapace, S.; Perseghin, G.; Molon, G.; Canali, G.; Bertolini, L.; Zoppini, G.; Barbieri, E.; Targher, G. Nonalcoholic fatty liver disease is associated with left ventricular diastolic dysfunction in patients with type 2 diabetes. Diabetes Care, 2012, 35 (2), 389-95.

4. Björnsson, E.; Treeprasertsuk, S.; Treeprasertsuk, S. NAFLD fibrosis score: a prognostic predictor for mortality and 
liver complications among NAFLD patients. World J Gastroenterol, 2013, 19(8), 1219-1229.

5. Buziashvili, Y. I.; Buziashvili, V. Y. Possibilities of modern methods of visualizations in patients with ischemic heart disease. Cardiosomatics. 2014, 3-4, 20-26.

6. Cohn, J. N. Arteries, myocardium, blood pressure and cardiovascular risk: towards a revised definition of hypertension. $J$. Hypertens, 1998, 16, 12, Pt. 2., 21172124.

7. Cunningham, K. S.; Veinot, J. P.; Butany, J. An approach to endomyocardial biopsy interpretation. J. Clin. Pathology, 2006, 59(2), 121-129.

8. Drapkina, O. M. PAAC and fibrosis. Hepato-cardiac relations. Russian medical journal, 2011, 19(18), 1136-1139.

9. Lazebnik, L. B.; Radchenko, V. G.; Golovanova, E. V. Zvenigorodskaya, L. A.; Konev, Yu. V.; Seliverstov, P. V.; Sitkin, S. I.; Tkachenko E. I.; Avaluyeva, E. B.; Aylamazyan, E. K.; Vlasov, N. N.; Grinevich, V. B.; Korniyenko, E. A.; Novikova, V. P.; Khoroshinina, L. P.; Zhestkova, N. V.; Oreshko, L. S.; Dudanova, O. P.; Dobritsa, V. P. Nonalcoholic fatty liver disease: clinics, diagnostics, treatment (recommendations for therapists, 2nd edition). Therapy, 2017. 3, p.5-23.

10. Mantovani, A.; Pernigo, M.; Bergamini, C.; Bonapace, S.; Lipari, P.; Pichiri, I.; Bertolini, L.; Valbusa, F.; Barbieri, E.; Zoppini, G.; Bonora, E.; Targher, G. Nonalcoholic Fatty Liver Disease Is Independently Associated with Early Left Ventricular Diastolic Dysfunction in Patients with Type 2 Diabetes. PLOS ONE, 2015, 10(8), 234-239.

11. Musso, G.; Cassader, M.; Rosina, F.; Gambino, R. Impact of current treatments on liver disease, glucose metabolism and cardiovascular risk in non-alcoholic fatty liver disease (NAFLD): a systematic review and meta-analysis of randomized trials. Diabetologia, 2012, 55(4), 885904.
12. Nikiforov, V.S. Methods of cardiovascular visualization in the diagnostics of ischemic heart disease. Consilium medicum, 2017, (01), 18-24.

13. Parmon, E. V.; Ryzhova, D.V. Evaluation of the metabolism and perfusion of myocardium in patient with noncoronarogenic ventricular rhythm disturbances. Arterial hypertension, 2014, 20(3), 189-200.

14. Roytberg, G. E.; Sharkhun, O. O. Evaluation of the risk factors for nonalcoholic fatty liver disease. Practicing doctor, 2017a, 1, 58-62.

15. Ryotberg, G. E.; Sharkhun, O. O. Peculiarities of the progression of liver damage in patients with insulin resistance. Medical almanac, 2017b, 1 (46), 65-68.

16. Sergienko, V. B.; Babev, F. Z. Positronemission tomography in the evaluation of metabolism of the myocardium. Atherosclerosis and dyslipidemia, 2011, 26-31.

17. Usov, V. U.; Arkhangelskiy, V. A.; Fedorenko, E. V. The evaluation of viability of the damaged myocardium in cardiosurgical patients: comparison of the possibilities of magnet-resonance and emission tomography. Complex problems of cardiovascular diseases, 2014, 3, 124132.

18. Yamamoto, S.; James, T. N.; Kawamura, K.; Nobuyoshi, M. Cardiocytic apoptosis and cappilary endothelian swelling as morphological evidence of myocardial ischemia in ventricular biopsies from patients with angina and normal arteriograms. Coron. Artery Dis, 2002. 13(1), 25-35.

19. Yoshinaga, R.; Tamaki, N. Imaging myocardial metabolism. Gurr. Opin.Biotechnoll, 2007, 18i, 52-59. 


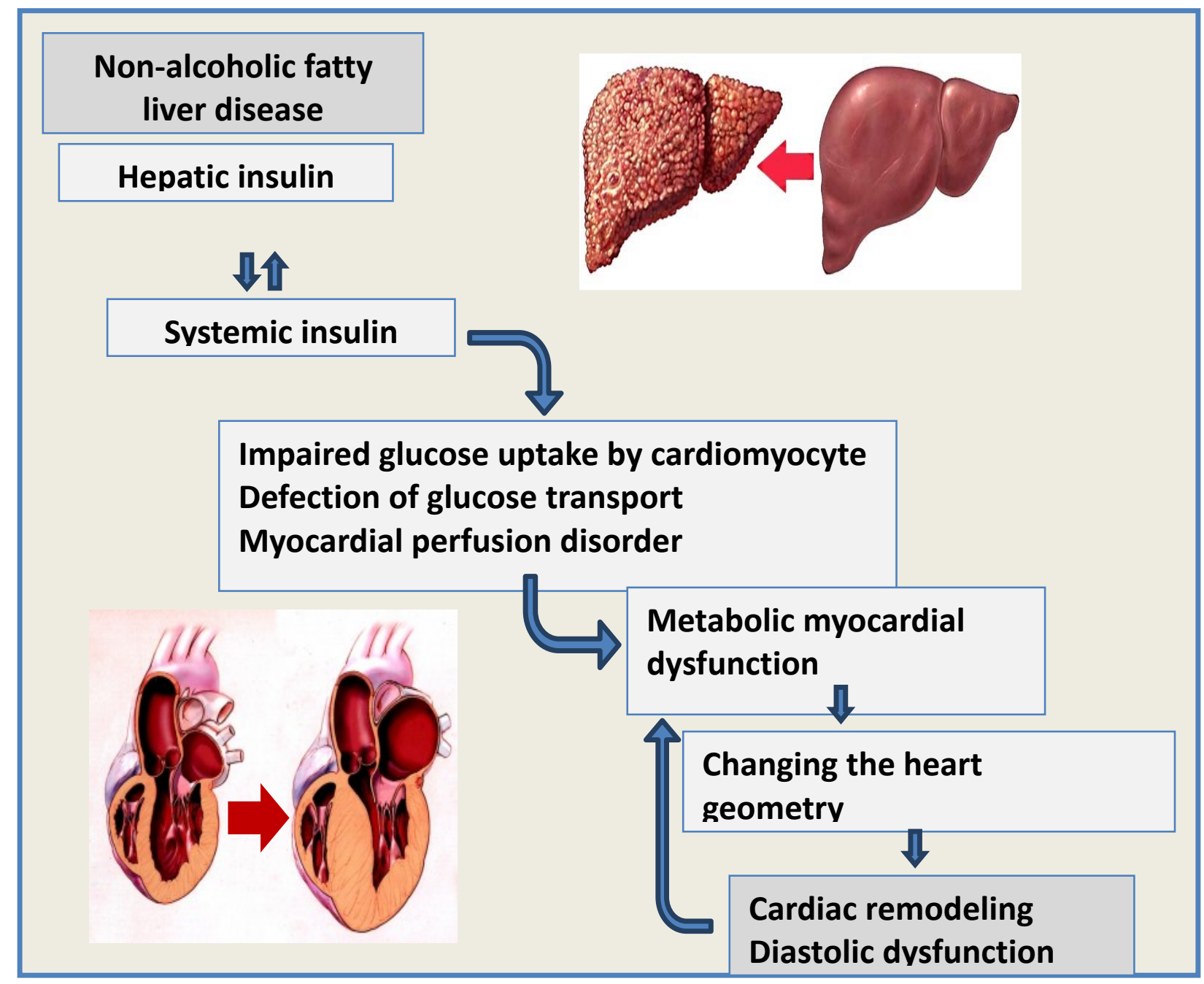

Figure 1. Development of Hepato-cardiac relations in patients with NAFLD and insulin resistance. 